\title{
A Reforma Cabanis como pauta da idéologie: faculdades imperiais em vez de universidades góticas
}

\author{
Naomar Almeida-Filho
}

\begin{abstract}
Resumo:
Neste artigo, pretendo avaliar como, extrapolando o campo da saúde, a Reforma Cabanis foi incorporada à reforma educacional bonapartista que estabeleceu as bases institucionais do sistema de ensino superior implantado na França, durante o século XIX. Nesse sentido, em primeiro lugar, apresento os principais pontos da reforma do ensino médico, destacando dimensões conceituais e político-pedagógicas da contribuição de Cabanis e seus parceiros - membros do movimento que se tornou conhecido como Idéologie -, principalmente no que se refere à potencial articulação com o sistema de educação em geral. Em segundo lugar, identifico eventos históricos referentes à reorganização do sistema francês de educação, no contexto das reformas sociais iniciadas no regime do Consulado, consolidadas no Império e mantidas na Restauração. Em terceiro lugar, analiso a configuração do modelo resultante dessas reformas, destacando o conceito de universidade imperial, promovido pelo próprio Imperador Napoleão Bonaparte como centro gestor de todo o sistema de educação. Finalmente, faço referência à reforma universitária republicana, aprovada na década de 1890, quando as universidades foram reincorporadas ao sistema francês de educação como instância de representação institucional e coordenação simbólica de faculdades, escolas e academias que detinham autonomia política, administrativa e acadêmica.
\end{abstract}

Palavras-chave:

Cabanis; Bonaparte; reforma universitária; educação superior 


\title{
Cabanis Reform as an Agenda for the Idéologie: Imperial faculties instead of gothic universities
}

\begin{abstract}
In this paper, I intend to evaluate how, beyond the health field, Cabanis Reform was incorporated into the Bonapartist educational reform that established the institutional foundations of the higher education system implanted in France during the 19th century. With this aim, I first present the main points of the medical education reform, highlighting conceptual and politico-pedagogical dimensions of the contribution of Cabanis and his partners - members of the movement that became known as Idéologie -, especially in relation to its potential articulation with the education system in general. Secondly, I identify historical events related to the French education system reorganization, in the context of social reforms that begun in the Consulate regime, consolidated in the Empire and was maintained in the Restoration. Thirdly, I analyze the configuration of the model resulting from such reforms, emphasizing the concept of Imperial University, promoted by the Emperor Napoleon Bonaparte himself as the manager centre of the entire education system. Finally, I refer to the republican university reform approved in the 1890s when universities were reincorporated into the French education system as an instance of institutional representation and symbolic coordination of faculties, schools, and academies that held political, administrative, and academic autonomy.
\end{abstract}

Keywords: Cabanis; Bonaparte; university reform; higher education

\section{La Réforme Cabanis comme programme pour l'Idéologie: facultés impériales au lieu d'universités gothiques}

Résumé: Dans cet article, je compte évaluer dans quelle mesure, extrapolant le domaine de la santé, la réforme Cabanis a été intégrée dans la réforme bonapartiste de l'éducation qui a jeté les bases institutionnelles du système d'enseignement supérieur introduit en France au cours du XIXe siècle. À cet égard, tout d'abord, je vous présente les principaux points de la réforme de l'éducation médicale, mettant l'accent sur les dimensions conceptuelles et politico pédagogiques de la contribution de Cabanis et ses collègues - membres du mouvement qui est devenu connu sous le nom l'Idéologie - principalement en ce qui concerne à l'articulation avec le système éducatif en général. En second lieu, j'identifie quelques événements historiques liées à la réorganisation du système éducatif français, dans le cadre des réformes sociales engagées dans le régime du consulat et consolidés dans l'Empire et la Restauration. Troisièmement, j'analyse la configuration du modèle résultant de ces réformes, mettant en lumière le concept d'Université Impériale, promu par l'empereur Napoléon Bonaparte lui-même comme un centre de gestion de l'ensemble du système éducatif. Enfin, je me réfère à la réforme de l'université républicaine, adoptée dans les années 1890, lorsque les universités ont été réincorporés dans le système éducatif français comme une instance de représentation institutionnelle et coordination symbolique des facultés, des écoles et des académies qui avaient une autonomie politique, administrative et académique.

Mots clés: Cabanis; Bonaparte; réforme universitaire; enseignement supérieur

\section{La Reforma Cabanis como pauta de la Idéologie: facultades imperiales en vez de universidades góticas}

Resumen: En este artículo, pretendo evaluar cómo, extrapolando el campo de la salud, la Reforma Cabanis fue incorporada a la reforma educativa bonapartista que estableció las bases institucionales del sistema de enseñanza superior implantado en Francia, durante el siglo XIX. En ese sentido, en primer lugar, presento los principales puntos de la reforma de la enseñanza médica, destacando dimensiones conceptuales y político-pedagógicas de la contribución de Cabanis y sus colegas - miembros del movimiento que se hizo conocido como Idéologie -, principalmente en lo que se refiere a la articulación con el sistema de educación en general. En segundo lugar, identifico acontecimientos históricos referentes a la reorganización del sistema francés de educación, en el contexto de las reformas sociales iniciadas en el régimen del Consulado, consolidadas en el Imperio y mantenidas en la Restauración. En tercer lugar, analizo la configuración del modelo resultante de esas reformas, destacando el concepto de universidad imperial, promovido por el propio Emperador Napoleón Bonaparte como centro gestor de todo el sistema de educación. Finalmente, hago referencia a la reforma universitaria republicana, aprobada en la década de 1890, cuando las universidades fueron reincorporadas al sistema francés de educación como instancia de representación institucional y coordinación simbólica de facultades, escuelas y academias que tenían autonomía política, administrativa y académica.

Palabras clave: Cabanis; Bonaparte; reforma universitaria; educación superior 
Para a organização desses estabelecimentos [de ensino superior], introduzamos, como se deseja, relações íntimas entre eles, reuniões multiplicadas e um centro de direção, correspondência e movimento; não é certo que, nessa máquina assim montada, serão ajuntadas não somente as universidades góticas e as academias aristocráticas, mas ainda se apresentará um amontoado muito mais considerável do que havia quando se sentiu a necessidade de destruir as instituições da realeza. ${ }^{1}$ (Antoine-François, Conde de Fourcroy, 1793, p.2, itálicos nossos)

A instituição de um modelo de educação superior sem "góticas universidades", laico, moderno, profissionalizante e especializado, na virada do século XIX, tinha por objetivo não somente destruir as odiadas "instituições da realeza", mas também atender às necessidades da nascente revolução industrial e às demandas por quadros dirigentes para compor a burocracia do estado republicano, recém-inaugurado pela Revolução Francesa de 1789. Em apenas seis anos, entre 1794 e 1800, intensa construção intelectual, mobilização social, atuação parlamentar, em geral, competente e coordenada, de alguns brilhantes intelectuais e políticos influentes - muitos deles integrantes do movimento que se tornou conhecido como Idéologie, como veremos adiante - que contribuíram para a formação duma complexa rede nacional de instituições de pesquisa e de ensino superior. Essa rede era inicialmente formada por escolas de saúde, sociedades científicas e faculdades de medicina, institutos e academias, em seguida escolas de direito, escolas politécnicas, escolas normais e colégios especiais de ensino superior; nesse cenário, não havia universidades, extintas pela Assembléia em 1793 (Charle \& Verger, 2012). Dessa forma, o novo regime passou a contar com uma estrutura de educação dominada pelas novas profissões legitimadas e controladas pelo Estado burguês, conservando os atrativos das tradições acadêmicas que tinham sido proscritas pela Revolução Francesa, mas que seriam rapidamente restauradas na era napoleônica e mantidas nos governos que se sucederam no decorrer do século XIX.

Considerando a ativa participação do médico, poeta e político Pierre-Jean Georges Cabanis [1757-1808] nesse processo, propus designar como Reforma Cabanis ao conjunto de iniciativas para criar um novo modelo de ensino médico que inspirou e induziu profundas transformações no cenário da educação superior na conjuntura da França pós-revolucionária (Almeida-Filho, 2017). No presente artigo, segundo de uma série (Almeida-Filho, 2018), pretendo avaliar como, extrapolando o campo da saúde, a 
Reforma Cabanis foi incorporada à reforma educacional bonapartista que estabeleceu as bases institucionais do sistema de ensino superior implantado na França, durante o século XIX. Nesse sentido, em primeiro lugar, apresento os principais pontos da reforma do ensino médico, destacando dimensões conceituais e político-pedagógicas da contribuição de Cabanis e seus parceiros - membros do movimento que se tornou conhecido como Idéologie -, principalmente no que se refere à potencial articulação com o sistema de educação em geral. Em segundo lugar, identifico eventos históricos referentes à reorganização do sistema francês de educação, no contexto das reformas sociais iniciadas no regime do Consulado, consolidadas no Império e mantidas na Restauração. Em terceiro lugar, analiso a configuração do modelo resultante dessas reformas, destacando o conceito de Universidade Imperial, promovido pelo próprio Imperador Napoleão Bonaparte como centro gestor de todo o sistema de educação. Finalmente, faço referência à reforma universitária republicana, aprovada na década de 1890, quando as universidades foram reincorporadas ao sistema francês de educação como instância de representação institucional e coordenação simbólica de faculdades, escolas e academias que detinham autonomia política, administrativa e acadêmica.

\section{Reforma Cabanis: pedagogia política da Idéologie}

Originalmente, a Reforma Cabanis tinha como foco o ensino médico (Almeida-FiIho, 2017). Propunha um modelo de ensino que, sintetizado em diferentes propostas e documentos, compreendia cinco elementos estruturantes: (a) modelo organizacional fragmentado em faculdades, escolas e institutos, dispensando a figura institucional de universidade; (b) viés profissionalista, com certificação oficial dos graus acadêmicos numa política de formação profissional em saúde; (c) apropriação de espaços externos e laicos, trazendo-os para controle institucional e ajustando-os às atividades próprias de ensino-aprendizagem; (d) estrutura curricular programada e linear, orientada pela disciplinaridade, formada por cátedras, matérias e disciplinas; (e) pedagogia analítica, tendo como horizonte a especialização.

Entretanto, considerando o capital político acumulado pelos médicos na luta revolucionária e seus desdobramentos, além da centralidade da ciência e da medicina no imaginário da sociedade burguesa emergente, essa reforma extrapolou o campo da saúde e efetivamente influenciou a recriação do ensino superior no período pré-Bonaparte, da Convenção ao Diretório. Ademais, o próprio Cabanis sempre demonstrou interesse pessoal em contribuir para a realização do grande projeto de vida de Mirabeau e Condorcet, seus saudosos amigos e parceiros políticos: a reorganização do sistema francês de ensino em todos os setores e níveis (Cabanis, 1797). No introito ao Coup d'oeil sur les Revolutions et Réforme de la Médecine, refere que seu amigo Garat, na posição de Comissário da Instrução Pública designado pela Convenção, interessado 
em suas ideias sobre como aplicar o método analítico às ciências médicas, o teria convidado a participar de um projeto maior: tornar a educação fator imprescindível à consolidação da nova democracia (Cabanis, 1804). A demanda de Garat simplesmente o encorajou a avançar num ambicioso projeto, eminentemente político: nada menos que a libertação da espécie humana (Saad, 2016).

Em meados de 1794, quando o Terror finalmente retrocedeu, Cabanis reabriu os salons de Auteuil. Juntamente com Garat e Desttut de Tracy, formou um grupo de intelectuais parisienses engajados na construção de uma nova sociedade regida pelos princípios revolucionários de liberdade, igualdade e fraternidade que a imprensa napoleônica chamaria, pejorativamente, de "ideólogos" (Pouliquen, 2013). O núcleo aglutinador compunha-se de extraordinárias personalidades de grande presença no cenário europeu da virada do século - Jean-Baptiste Say, pioneiro das ciências econômicas; Pierre-Simon Laplace, célebre matemático, astrônomo e físico; Constantin-François de Volney, historiador orientalista, que introduziu Napoleão Bonaparte ao grupo; Pierre-Claude François Daunou, educador e precursor da ciência política; Philippe Pinel, médico e fundador da psiquiatria moderna - liderados por Destutt de Tracy, Dominique Garat e pelo próprio Cabanis. Em bloco, os ideólogos compuseram o Institut Nacional de France, órgão de política científica e educacional inaugurado em 1795, concebido como iniciativa atualizadora das "aristocráticas academias" extintas pela Revolução. Como efeito da atuação específica do grupo, as academias foram gradualmente restauradas mediante o reconhecimento das diversas classes do Institut, sendo primeira a classe (onde atuava Cabanis) de Língua Francesa e Literatura que, a partir de 1816, se tornaria a Académie Française (Pouliquen, 2013).

Cabanis e seus colegas lançaram-se num processo coletivo de preparação intelectual para uma cruzada político-ideológica, buscando aplicar aos conhecimentos humanos os métodos analíticos formulados por Descartes, Locke e Condillac, tendo como foco principal a medicina e a educação. Aos ideólogos interessava sobremaneira a teoria sensualista do conhecimento elaborada pelo Abade Etienne de Condillac, sintetizada como aplicação política e pedagógica por Condorcet (1794) no Esquisse d'un tableau historique de progrès de l'esprit humain Posteriormente, o próprio Cabanis (1802) contribuiria decisivamente para aprofundar essa perspectiva naturalista do entendimento humano, com uma abordagem original da questão cartesiana da relação corpo-mente na sua obra filosófica maior, o Rapports du physique et du moral de l'homme.

Note-se que o sentido de 'físico' e de 'moral' em Cabanis não implica polos estabelecidos numa dualidade excludente, na medida em que se interdefinem justamente pela situação de rapport inseparável, radicalmente imbricados em demandas, determinações, dinâmicas e especificidades do mundo histórico, do corpo político e da vida social. Para Cabanis, o substrato físico-químico-biológico do ser humano e sua 
ecologia não pode ser reduzido à esfera simbólico-cultural da existência humana, pois o moral é físico e o físico, moral. Longe de ser compreendido separadamente pelo estudo histórico de normas e leis, o "ponto de vista moral" precisa ser entendido de modo ampliado, para além do que o senso-comum contemporâneo engloba na série significante ética-moralidade-moralismo. Nessa perspectiva, o sentido de moral equivale mais às referências psico-socio-culturais da existência humana, fundamentos para uma science de l'homme, equivalente ao que a filosofia alemã chamaria de antropologia, segundo o próprio Cabanis (1804, p.23).

As ideias de progresso social e de perfectibilité (termo cunhado pelo filósofo suíço Jean-Jacques Rousseau para designar uma tendência à busca da perfeição, inata entre os humanos) e suas implicações também foram objeto de intensos debates entre os ideólogos (Saad, 2016, p.235). Cabanis explicitou seus argumentos numa carta ao editor publicada em La Décade philosophique, periódico onde os ideólogos divulgavam os principais textos gerados em seus acalorados debates (Cabanis, 1799). O texto replicava pontos centrais do Coup d'oeil (que tinham sido apresentados ao Institut de France) como resposta a críticas precoces aos ideólogos, acusados de serem defensores de um materialismo mecânico, numa perspectiva ateísta da perfectibilidade possível sem presença da divindade. Então, Cabanis defendia que os seres humanos seriam tendencialmente orientados à perfectibilidade, simultaneamente natural e cultural, no sentido de constante busca de melhoria como indivíduo e como espécie (no léxico da época, ele usa o termo race), nos dois aspectos, físico e moral. O primeiro envolve uma evolução da saúde física e das capacidades individuais herdadas, numa perspectiva claramente lamarckiana. ${ }^{2}$ A hereditariedade das características adquiridas significava que os seres humanos seriam capazes de transformar suas próprias naturezas para que, ao longo de várias gerações, "não existam os mesmos homens nem a mesma raça"; desenvolvimentos sociais, morais e políticos introduziriam uma grande distância entre os diferentes homens com "disposições primitivas iguais". O segundo aspecto se refere à determinação social do aperfeiçoamento humano, para Cabanis (1804) viabilizado por políticas educacionais universalistas, pois a educação "desenvolve a inteligência, cultiva afeições [e] dirige todas as tendências da natureza ao objetivo mais útil de garantir a felicidade de cada um e de todos" (p.26).

Mais uma vez em convergência com Mirabeau e Condorcet, antecipando em quase dois séculos a noção contemporânea de "democracia cognitiva", os ideólogos defendiam que somente haveria progresso social com igualdade intelectual para todos os seres humanos, mediante acesso amplo ao conhecimento por meio de uma educação libertadora (Saad, 2016). Cabanis e seus colegas ideólogos consideravam a instrução pública como crucial numa república moderna fundada nos princípios da liberdade e da igualdade individuais, na medida em que o sistema democrático dependia de que todos os cidadãos tivessem uma compreensão adequada de seus direitos e deveres, 
bem como plena capacidade para participar dos processos deliberativos, da avaliação de dirigentes e do julgamento da representatividade política.

Dessa forma, do ponto de vista de uma teoria social da educação, portanto, a Reforma Cabanis se apresentava como uma pedagogia política (Gaille, 2012). Sua realização implicaria um novo uso da retórica como didática (Pender, 2012), em três aspectos: Primeiro, em vários momentos de sua obra, Cabanis foi claro ao rejeitar uma instrumentalização da retórica nas estratégias pedagógicas de formação no campo da saúde, não reconhecendo eficácia didática na doutrina autorizada pela tradição médica. Segundo, a metáfora do pensamento como secreção fisiológica e do conhecimento como matéria física, um dos argumentos centrais do Raports (Cabanis, 1802), junto com uma atualização da metódica cartesiana, apresentada no Coup d'oeil (Cabanis, 1804), justificaria a fragmentação sistemática tanto do processo de formação quanto do objeto de ensino-aprendizagem. De fato, o modelo de formação resultante se baseava numa apologia da disciplinaridade como modo de organização e catalogação do conhecimento humano numa estrutura racional e sistemática herdada da gramática de Port-Royal, mediado pelo enciclopedismo. Por último, postulava uma reorganização da lógica (no caso, lógica indiciária) na formulação do raciocínio diagnóstico baseado em sinais e sintomas no processo de constituição de uma retórica adequada a um novo objeto da clínica (Ginzburg, 1989, p.177).

Nesse complexo processo coletivo de invenção de um novo regime jurídico e institucional para o nascente Estado republicano, a Reforma Cabanis postulava que, por um lado, pertinência, qualidade, utilidade e validade da matéria objeto da instrução seriam julgadas por academias e corporações profissionais; em paralelo, produção de pesquisa e desenvolvimento tecnológico poderiam ser melhor conduzidos e coordenados por sociedades científicas ou organismos estatais. Nesse contexto, a Reforma Cabanis resultou enfim em faculdades dotadas de autonomia e capacidade para decidir de modo independente sobre normas, disciplinas e cursos, deslocando a universidade como eixo institucional da educação superior na ordem social do capitalismo emergente no advento da modernidade (Almeida-Filho, 2018).

\section{A Reforma Educacional de Bonaparte}

Justamente na ruptura dessa fase histórica - uma sociedade liberal pós-aristocrática resultante de um novo modo de produção - a Reforma Cabanis viabilizou, na esfera do ensino médico, a emergência do chamado regime linear de formação (Almeida-Filho, 2017). Para consolidar esse quadro, faltava apenas reorganizar o arcabouço geral do sistema de educação, capaz de cuidar da reprodução de um novo regime que se livrara da velha ordem aristocrática, mas que, de fato, não tinha como projeto político priorizar os segmentos sociais pobres, oprimidos e explorados pelo modo de 
produção emergente. Essa etapa seria cumprida em seguida, na ampla reforma educacional viabilizada por Napoleão Bonaparte [1769-1821].

O jovem general Bonaparte participava com entusiasmo dos debates promovidos no salon de Auteuil, principal ponto de encontro dos ideólogos, demonstrando grande simpatia pelas propostas moderadas do grupo. Em 1799, após uma série de campanhas militares vitoriosas, aclamado como salvador da pátria, Napoleão protagonizou um coup d'état, conhecido como o Golpe do 18 Brumário, que estabeleceu um sistema de governo chamado Consulado, sendo escolhido pelo Diretório como primeiro cônsul da República (Chateranne \& Papot, 2012). Como um dos mais influentes membros do Conselho dos Quinhentos, Cabanis participou ativamente das articulações e foi o principal relator do manifesto à nação que anunciou a tomada do poder (Role \& Boulet, 1994).

O Círculo de Auteuil, já reconhecido por Napoleão como importante núcleo de debate intelectual, apoiou o Consulado na formulação das proposta de reforma em todos os níveis, da profissionalização das forças armadas à organização da burocracia pública, da assistência social à medicina urbana, do código civil ao sistema de educação (Pouliquen, 2013). Compreensivelmente, a reforma educacional se destacava na lista de prioridades de Napoleão, que atendia em grande parte às demandas da nova classe média burguesa e aos interesses políticos de uma aliança com a maioria católica da sociedade francesa, bem como às pretensões de tornar a França uma potência bélica e industrial, consolidando-a como centro mundial de produção científica e tecnológica (Chateranne \& Papot, 2012).

Em maio de 1802, um decreto estabeleceu um novo sistema de educação que se tornaria a base para o modelo ainda hoje vigente na França e em vários países de cultura latino-mediterrânea. No nível primário, écoles populaires seriam responsabilidade municipal. A rede de escolas secundárias estaria sob a direção de uma autoridade central, incluindo escolas particulares e clericais, controladas pelo estado. Após um acordo com o Vaticano, Napoleão restabeleceu a educação religiosa e permitiu que algumas escolas fossem geridas por ordens religiosas (Markham, 2010). Napoleão pessoalmente esboçou o sistema de ensino secundário que distinguia a instrução pública para carreiras civis e militares. Carreiras civis estudavam línguas, retórica e filosofia; a educação militar enfatizava matemática, física, química e matérias militares específicas, como balística, logística, estratégia.

O ponto forte do novo sistema de educação era uma rede de lycées, mantidos pelo Estado, substituindo as écoles centrales do Plano Daunou, buscando ampliar oportunidades educacionais aos egressos das escolas secundárias (Boudon, 2004). Precursores dos liberal arts colleges dos Estados Unidos, os liceus originalmente foram concebidos como transição entre a educação básica e o ensino superior; para isso, seu currículo incluía línguas, literatura moderna, artes, ciências e outros estudos 
necessários a uma educação "liberal burguesa". O novo sistema tinha como objetivo formar uma elite de quadros civis e militares, a partir de uma classe média economicamente bem-sucedida na conjuntura pós-revolucionária. Bolsas de estudos eram fornecidas aos melhores alunos das escolas secundárias, com prioridade para filhos de militares e funcionários do governo. O governo deveria proporcionar um salário fixo para os professores, mas também previa fornecer bônus e outros incentivos para professores bem-sucedidos. Havia grande ênfase ao patriotismo nas escolas, em paralelo ao grau de controle e centralismo do novo regime sobre todo o sistema educacional, o que aumentaria durante os anos do império. O clima exacerbado de belicosidade e patriotismo, a revelação das tendências autoritárias de Napoleão, agora Consul Vitalício da República, seu pacto com o clero católico e, particularmente, a rejeição do programa da Idéologie no que se referia a educação e à pesquisa científica, provocaram o afastamento dos ideólogos que, em sua maioria passaram a se posicionar, individualmente e como grupo, em franca oposição ao regime bonapartista (Pouliquen, 2013).

Como muitos dos seus colegas, Cabanis esperava que os princípios republicanos seriam valorizados e aplicados na reconstrução da sociedade francesa, mas decepcionou-se com as decisões autocráticas do futuro Imperador Napoleão; em protesto, a partir de 1802, retirou-se da vida pública. Mesmo afastado, Cabanis mantinha grande prestígio e exercia forte influência no cenário intelectual parisiense. A despeito disso, para Jacques-Olivier Boudon (2004), reconhecido especialista em historiografia da era napoleônica, o verdadeiro maître d'oeuvre da reforma educacional bonapartista foi Antoine de Fourcroy. Revolucionário atuante, personagem maior na política educacional, científica e cultural da Convenção, foi recrutado pessoalmente por Bonaparte para o Conselho de Estado do Consulado. Naquele momento, Fourcroy já se encontrava distanciado dos ideólogos e teria renegado publicamente seu próprio plano de reforma do ensino médico, de resto suplantado pelo avanço da Reforma Cabanis. A partir de 1802, assumiu a Direção Geral de Instrução Pública, com a missão de elaborar, negociar e defender nos plenários deliberativos uma lei de reforma da educação para todo o Império.

\section{A Universidade Imperial}

Em dezembro de 1804, coroado Imperador da França, Napoleão aprofundou a série de reformas sociais iniciadas no Consulado (Chateranne; Papot, 2012). Particularmente preocupado com a independência das escolas secundárias e dos liceus, ao consolidar o controle político do país, buscava estabelecer um regime ainda mais centralizado de gestão do sistema educacional francês. Com essa intenção, incluiu na reforma educacional o conceito de "Universidade Imperial", inicialmente definido como uma congregação nacional de docentes, numa carreira de serviço público exclusiva do 
Estado. Consolidado por Fourcroy, o projeto de reforma da educação entrou na pauta do Conselho de Estado em fevereiro de 1806. Os debates se desenvolveram durante meses, com ativa participação de Napoleão, que insistia na ideia de que a universidade "virtual" assim criada deveria ter plena autonomia em relação aos ministérios, já que responderia diretamente ao Imperador (Boudon, 2006). Fourcroy defendeu que a lei proposta não negava, e sim aperfeiçoava, a legislação anterior que ele, em grande medida, ajudara a formular. Em suas palavras, seria um despropósito destruir as novas instituições, unindo os vários organismos, visando a estabelecer as relações necessárias com a administração geral. Seu pronunciamento final na Assembleia Legislativa, registrado por Cambacères (apud Boudon, 2004, nota 11) termina com um elogio desabrido ao Imperador, aclamado como "grande homem que, não contente de ter iluminado seu século e feito a felicidade de seus contemporâneos, prepara os altos destinos da geração que deverá nos suceder". ${ }^{3}$

Nesse mesmo registro de franca bajulação, dirigindo-se ao Imperador Napoleão ainda em 1806, Fourcroy the concede todo o crédito pela ideia da Universidade Imperial como "único meio de salvar a própria educação pública da ruína total" (Aulard, 1911, p.152):

Os restos das antigas corporações docentes foram suficientes até agora para sustentar o edifício; mas esses recursos se esgotam todos os dias [...]. Uma corporação, como a que Vossa Majestade concebeu e planejou, pode sozinha regenerar a educação pública e garantir a prosperidade (Aulard, 1911, p.153)

A Lei da Reforma Educacional foi finalmente aprovada pela Assembleia Legislativa em 10 de maio de 1806, com a seguinte redação do seu Artigo 1: Será formado, sob o nome de Universidade Imperial, um corpo encarregado exclusivamente do ensino público e da educação em todo o Império. ${ }^{5}$ Nesse sistema, que ficou conhecido como "monopólio universitário" (Aulard, 1911), nenhuma instituição educacional podia ser estabelecida fora da Universidade Imperial, ninguém poderia abrir uma escola ou atuar no ensino sem ser membro do corpo docente da Universidade e sem ter se graduado em uma de suas faculdades ou escolas superiores.

O Décret d'application dessa lei somente foi publicado em 1808, acrescentando à definição de Universidade Imperial o caráter de órgão de Estado que detinha a exclusividade das atividades de educação, integrando e controlando todas as instituições educacionais de todo o Império, compreendendo um corpo docente com dedicação exclusiva ao ensino (Boudon, 2006). Nesse decreto, definia-se também a estrutura hierárquica do sistema de ensino como um todo, composto por diferentes tipos de instituição educacional: collèges - escolas secundárias municipais ou comunais, 
ensinando francês, latim, geografia, história e matemática; instituts - escolas independentes de nível mais ou menos equivalente aos colégios; écoles normales -destinadas à formação de professores para o ensino primário; lycées - escolas mantidas pelo Estado, com internato, pensionato e bolsas de estudo, ministrando um curso de seis anos, com foco em estudos clássicos e matemática; grandes écoles - encarregadas do ensino superior em carreiras científicas e acadêmicas clássicas; facultés - únicas instituições autorizadas a formar quadros nas profissões de maior prestígio social e capital político da época: Direito e Medicina. O que hoje se chamaria de formação técnica profissionalizante era realizada numa categoria especial, o Lycée des Arts et Métiers, e a formação em nível superior nas Engenharias e carreiras militares em écoles polytechniques.

Essa ideia peculiar, uma Universidade Imperial, simultaneamente organismo de controle geral da rede de ensino de um dado território e corpo único de professores de todo o sistema educacional, não tem paralelo na história ocidental. Mesmo na França, não sobreviveu ao próprio Napoleão, na medida em que, a partir de 1815, o órgão maior do sistema educacional francês deixou de ser designado como Université Impériale e passou a se chamar Commission nationale d'Instruction publique e seus professores tiveram sua lotação distribuída na rede institucional dos territórios (Boudon, 2006). Em reação ao rigoroso controle estatal durante a era napoleônica, tão logo se questionou a competência legal da Universidade Imperial, diversos órgãos dedicados à educação superior se retiraram do sistema unificado de educação, conquistando sua autonomia institucional como academias, escolas, institutos e faculdades isoladas (Charle \& Verger, 2012).

Boudon (2007) levantou dados referentes ao cenário da educação superior francesa naquele momento. Em 1815, metade dos 6.000 estudantes franceses de nível superior frequentavam uma das 9 faculdades de direito, concentrando-se quase um quarto de todos os estudantes em Paris. As três faculdades de medicina (Paris, Montpellier e Estrasburgo) registravam quase 1.200 alunos, enquanto as três escolas de farmácia acolhiam menos de 400 estudantes. Em 1813, havia somente 145 professores de ensino superior em todo o país, 89 em letras, 56 em ciências. Em 1814, as 21 faculdades de letras agrupavam 1.332 estudantes. A Faculdade de Letras de Paris, abrigada na Sorbonne, não era a mais importante do Império: tinha apenas 70 alunos matriculados, além dos estudantes da École normale superieure. As nove faculdades de ciências tinham um alunado muito menor, composto por 326 estudantes, porque a maioria dos alunos atraídos por carreiras científicas encontravam-se em escolas técnicas militares como a École Polytechnique de Paris.

Com um regime institucional dominado por academias, faculdades e escolas isoladas e relativamente independentes das universidades, é justamente nessa fase histórica que se introduz, em todo o subsistema de educação superior francês, uma 
arquitetura curricular exclusiva para formação profissional (Almeida-Filho, 2018). Essa medida foi consolidada nas reformas da medicina de 1802-1803 e nas reformas da educação de 1806-1808, culminando com a Universidade Imperial, num momento em que a sociedade francesa compactuava com o crescente controle governamental sobre a formação e a prática das novas categorias profissionais que buscavam consolidar sua hegemonia. Concretizado durante o período napoleônico e ampliado no Segundo Império, o modelo francês de ensino superior, além de confirmar a supressão da universidade, caracterizava-se igualmente pela forte segmentação de qualidade entre as várias unidades de educação superior e entre ensino profissional e formação acadêmica científica (Charle \& Verger, 2012).

\section{Restauração das universidades}

Somente na Terceira República, após a derrota frente aos alemães em Verdun, em 1870, modificações substanciais no sistema de educação superior permitiram a recuperação, ainda que parcial, da ideia de universidade na França. Cautelosa e gradualista, a nova reforma foi antecedida por uma série de decretos que concediam às faculdades autonomia para receber apoio financeiro, gerenciar recursos e criar cátedras e cursos (Weisz, 1983; Boudon, 2007). Com a autonomia, de fato, a independência administrativa das faculdades avançou, porém, os decanos continuavam nomeados pelo ministro, a partir de listas propostas pelas faculdades. Um decreto de $1885 \mathrm{criou}$, em cada faculdade ou grand école, dois órgãos deliberativos, a assembleia da faculdade e o conselho acadêmico. Um passo adicional foi dado por um decreto de 1889 que concedeu às faculdades orçamento próprio composto por taxa de inscrição e subvenções do orçamento do Estado.

Essa reforma culminou com uma lei aprovada pelo Parlamento em julho de 1896, que se tornou conhecida como Lei Liard, por ter sido proposta por Louis Liard, Diretor de Educação Superior a partir de 1884. A nova lei concedia personalidade jurídica ao corpo docente de faculdades agregadas como instituições e, para essas, autorizava o uso legal do nome 'universidade'. Nesse processo, de imediato ocorreu a refundação da Universidade de Paris-Sorbonne, em novembro de 1896, seguindo-se a criação de mais 15 universidades no interior do país (Boudon, 2007).

O próprio Liard (1890) sintetizou as bases dessa reforma num pequeno opúsculo intitulado Universités et Facultés, onde compara os dois formatos institucionais para demonstrar que a opção francesa pela educação superior baseada em faculdades teria sido um enorme equívoco histórico, a ser rapidamente corrigido. Posteriormente, reconhecendo superioridade no modelo norte-americano de educação superior, Liard (1894, p.III) propôs uma "teoria republicana da universidade", 
Concebida como um vasto organismo, uno e múltiplo ao mesmo tempo, uno como a mente humana a partir da qual vem toda a ciência, múltiplos como os vários objetos aos quais este espírito se aplica, aberto a tudo o que pode ser objeto de estudos e pesquisas, abstrações matemáticas, realidades físicas, realidades morais, criação literária, criações das artes, aplicações das ciências às artes técnicas, com tantos compartimentos quanto houver divisões naturais nas coisas, compartimentos distintos, mas não separados, nos quais circularia uma mesma vida, um mesmo espírito. ${ }^{6}$

A Reforma Liard, não obstante sólida argumentação, consistente formulação e cuidadoso encaminhamento, foi considerada um fracasso por historiadores da educação (Weisz, 1983; Boudon, 2007; Prost, 2009; Charle \& Verger, 2012). No modelo de ensino superior consolidado na Belle Époque, um século depois da supressão das "universidades góticas" pela Revolução de 1789, o poder das escolas continuava fortalecido, particularmente as chamadas faculdades superiores (Medicina e Direito, uma vez que a Faculdade de Teologia perdera espaço nas repúblicas oitocentistas) e nas escolas politécnicas. Com a hegemonia do ensino profissionalizante no modelo francês de ensino superior, restava às novas faculdades de letras e ciências a formação de professores. Nesse contexto, as novas universidades francesas tinham existência meramente nominal, na medida em que constituíam instância sem poder na prática, limitada à mediação política e à representação perante o Estado de um conjunto de faculdades que detinham autonomia financeira, administrativa, acadêmica e simbólica (Weisz, 1983).

Nas primeiras décadas do século XX, o modelo de ensino superior que se consolidou na França no século XIX rapidamente difundiu-se no espaço de influência cultural francesa, sobretudo em países mediterrâneos (e suas ex-colônias) de cultura latina, línguas românicas e matriz religiosa católica (Charles \& Verger, 2012). Na virada do século, tanto na matriz francesa quanto em países onde tal modelo de ensino superior prevalecia, resíduos e traços dos elementos anacrônicos dessa curiosa universidade republicana, renegada por dentro, a partir de suas próprias estruturas e funcionamento, indiciavam um formato institucional que remontava à Reforma Cabanis.

Não obstante, após a II Guerra Mundial, esse modelo sofreu rápida decadência, implodindo simbolicamente na revolta urbana do Maio de 1968, em Paris. Os motivos dessa decadência e crise são criticamente apresentados por Prost (2009):

Primeiro, uma concepção pobre e estreita das universidades, resumida ao ensino que produzem. A comparação com universidades estrangeiras é esmagadora neste ponto. Criar comunidades de vida e não apenas 
de aprendizado não estava na agenda dos republicanos, inspirados nos seminários alemães, não nos colleges anglo-saxões.

Em seguida, a força da tradição das Faculdades, simbolizada pelo retorno rápido, após 1968, do título de decano, do nome faculdade, e pela concomitante rarefação e precariedade das formações nas duas antigas faculdades. ${ }^{7}$

Em função de uma série de eventos que, na segunda metade do século XX, culminaram com o Processo de Bolonha, iniciado em 1999, mesmo os países europeus que tinham concebido ou adotado o modelo de educação superior concebido na Reforma Cabanis, paulatinamente abandonaram esse curioso sistema de ensino universitário sem universidades (Almeida-Filho, 2018).

\section{Comentários finais}

Como vimos, o modelo educacional concebido por Cabanis e seus colegas ideólogos foi parcialmente incorporado na reforma educacional bonapartista que, no decorrer do século XIX, estabeleceu as bases do sistema de ensino superior e profissional implantado na França, extrapolando o âmbito restrito da educação superior em saúde, priorizando o papel do Estado na instrução pública. Na sua formulação, a Reforma Cabanis traz uma dialética peculiar que, de modo discreto, configura uma ironia histórica que se reflete na posterior difusão da obra de Cabanis. Em trajetória de rápidos acontecimentos e vários desdobramentos, a Reforma Cabanis emerge de uma tradição filosófica em tese conservadora, contrapõe-se a um radicalismo político revolucionário, alimenta uma postura de crítica intelectual moderada, insere-se num processo de restauração econômico-social e ideológica, posiciona-se radicalmente contrária a uma ordem política totalitária e a um contexto social conservador e, de modo surpreendente, termina valorizada, acolhida e incorporada por movimentos políticos e teóricos que, em vários aspectos, são contraditórios entre si e com a própria perspectiva cabanisiana. Há mais de dois séculos, portanto, a Reforma Cabanis foi revolucionária.

O potencial disruptivo da contribuição de seu principal líder, Georges Cabanis, manifesto no conjunto de sua obra, objeto de numerosos relatórios e comunicados, provocou revoluções tecnocientíficas e políticas nos campos da saúde e do ensino médico, anunciadoras de uma reforma fundamental: a reforma da educação. Numa virada final, perseguido tanto pelo bonapartismo quanto pela restauração da Casa de Bourbon, o pensamento cabanisiano (nesse caso, em conjunto com seus pares da Idéologie) ressurgiu na primeira metade do século XIX, como tripla fonte de inspiração. Primeiro, no plano dos saberes e práticas de cuidado em saúde, as teorias de Cabanis contribuíram para a hegemonia de uma perspectiva materialista da filosofia da ciência 
e das ciências da vida, em geral, e das ciências da saúde, em particular. Segundo, no plano político senso-estrito, o pensamento-ação de Cabanis muito contribuiu para as teorias sociocríticas que inspiraram líderes revolucionários e movimentos políticos do século XIX. Por fim, no plano institucional e pedagógico, o modelo de educação superior gerado pela Reforma Cabanis tornou-se paradigmático na França e em outras nações submetidas à poderosa influência cultural francesa, principalmente na Europa meridional e em países recém-saídos da condição de colônia.

\section{Endnotes}

1 Introduisons, comme on le voulait encore, pour l'organisation de ces établissements, des relations intimes entre eux, des rassemblements multipliés, et un centre de direction, de correspondance et de mouvement; n'est-il pas évident que, dans cette machine ainsi montée, non seulement seront rassemblés les gothiques universités et les aristocratiques académies, mais encore qu'elle en présentera un amas beaucoup plus considérable qu'il n'était lorsqu'on a senti la nécessité de détruire ses institutions royales.

2 Conforme Staum (1980, p.187), Cabanis antecipou algumas ideias e, ao mesmo tempo, foi influenciado por seu contemporâneo Jean-Baptiste de Lamarck, famoso por conceber uma teoria de evolução das espécies mediante transmissão genética de caracteres adquiridos.

${ }^{3}[\ldots]$ grand homme qui, non content d'avoir illustré son siècle et fait le bonheur de ses contemporains, prépare de hautes destinées à la génération qui doit nous succéder.

${ }^{4}$ Les débris des anciennes corporations enseignantes ont su jusqu'à présent pour soutenir l'édifice ; mais ces ressources s'épuisent chaque jour [...]. Une corporation, telle que celle dont Votre Majesté a conçu la pensée et tracé le plan, peut donc seule régénérer l'instruction publique et assurer la prospérité.

5 II sera formé, sous le nom d'Université impériale, un corps chargé exclusivement de l'enseignement et de l'éducation publiques dans tout l'Empire.

6 Conçut comme un vaste organisme, un et multiple à la fois, un ainsi que l'esprit humain d'où vient tout science, multiple ainsi que les objets divers auxquels cet esprit s'applique, ouvert à tout ce qui peut être sujet d'études et de recherches, abstractions mathématiques, réalités physiques, réalités morales, création des lettres, créations des arts, applications des sciences aux arts techniques, avec autant de compartiments qu'il y a de divisions naturelles dans les choses, compartiments distinctes, mais non séparés, dans lesquels circulerait une même vie, un même esprit.

7 D'abord, une conception pauvre, étroite, des universités, résumées à l'enseignement qu'elles dispensent. La comparaison avec les universités étrangères est accablante sur ce point. Créer des communautés de vie et non seulement d'étude n'était pas au programme des républicains. Ils se sont inspirés des séminaires allemands, non des collèges anglo-saxons. [...] Ensuite, la force de la tradition facultaire, que symbolise le retour rapide après 1968 du titre de doyen, du nom de faculté, et la rareté comme la précarité des formations à cheval sur deux anciennes facultés.

\section{Referências Bibliográficas}

Almeida-Filho, N. (2017). O legado de Cabanis: hipótese sobre raízes da educação médica no Brasil. Cadernos de Saúde Pública, 33, Epub. e00206416.

Almeida-Filho, Naomar (2018). Reforma Cabanis (Circa 1800): uma reforma universitária sem universidades, esquecida na história da educação. Revista Lusófona de Educação 39, 41-54. doi: 10.24140/issn.1645-7250.rle39.03

Aulard, A. (1911). Napoléon ler et le monopole universitaire. Paris: Armand Colin. [Disponível em https:// archive.org/details/napolonieretle00aulauoft] 
Boudon, J-O. (dir.) (2004). Napoléon et les lycées. Enseignement et société en Europe au début du XIXe siècle. Paris: Nouveau Monde Éditions/Fondation Napoléon.

Boudon, J-O. (2007). La refondation de la Sorbonne au XIXe siècle. In: Robert Pitte (dir.). La Sorbonne au service des humanités. 750 ans (1257- 2007). (pp.53-66). Paris: PUPS.

Boudon, J-O. (2006). Napoléon, Organisateur de L'Université. Revue du Souvenir Napoléonien, 464. [Disponível em https://www.napoleon.org/histoire-des-2-empires/articles/napoleon-organisateurde-luniversite/].

Cabanis, P-J-G. (1956). Opinion sur un projet d'organisation des écoles primaires, et en général sur I'instruction publique. Claude Lehec; Jean Cazeneuve (eds.) Les œuvres philosophiques de Cabanis.

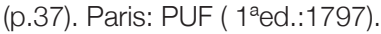

Cabanis, P-J-G. (1799). Lettre sur un passage de la "décade philosophique" sur la perfectibilité de l'esprit humain. La Décade philosophique, 21,149-59.

Cabanis, P-J-G. (1802). Rapports du physique et du moral de l'homme. [Disponível em http://gallica.bnf. fr/ark:/12148/bpt6k77029t.r=cabanis.langFR]

Cabanis, P-J-G. (1804). Coup d'oeil sur les Revolutions et Réforme de la Médecine. [Disponível em http://gallica.bnf.fr/ark:/12148/bpt6k76544v/f6.image].

Charle, C., Verger, J. (2012). Histoire des universités. Paris: PUF.

Chateranne, D. \& Papot, E. (2012). Napoleão: Sua Vida, Suas Batalhas, Seu Império. São Paulo: Agir.

Condorcet, N-C., Marquês de (1794). Esquisse d'un tableau historique de progrès de l'esprit humain. [Disponivel em https://fr.wikisource.org/wiki/Esquisse_d\%E2\%80\%99un_tableau_historique_des _progr\%C3\%A8s_de_l\%E2\%80\%99esprit_humain].

Fourcroy, A-F. (1793). Rapport et projet de décret sur l'établissement d'une Ecole centrale de santé à Paris. Paris: De l'Imprimerie nationale. [Disponivel em http://gallica.bnf.fr/ark:/12148/bpt6k48911v]

Gaille, M. (2014). Anthropologie médicale et pensée politique pour P.J. Georges Cabanis. Paris: CNRS Éditions.

Ginzburg, C. (1989). Sinais: raízes de um paradigma indiciário. Mitos, Emblemas e Sinais. São Paulo: Companhia das Letras.

Liard, L. (1890). Universités et Facultés. Paris: Colin. [Disponível em http://gallica.bnf.fr/ark:/12148/ bpt6k5449839g/f6.image].

Liard, L. (1894). L'enseignement supérieur en France (1789-1893). Paris: Colin. [Disponível em http:// gallica.bnf.fr/ark:/12148/bpt6k54526053/f528.image].

Markham, D. (2010). The Revolution, Napoleon, and Education. Paris: International Napoleonic Society. [Disponível em https://www.napoleon-series.org/research/society/c_education.html].

Pender, S. (2012). Between Medicine and Rhetoric. In: Stephen Pender, Nancy Struever (eds.) Rhetoric and Medicine in Early Modern Europe. Farnham: Ashgate.

Pouliquen, Y. (2013). Cabanis, un idéologue de Mirabeau à Bonaparte. Paris: Odile Jacob. 
Prost, A. (2009). Les Universités Françaises de 1808 à 1968. Paris: Académie de Sciences Morales et politiques, Communications. [Disponível em https://www.asmp.fr/travaux/communications/2009/ prost.htm].

Role, A. \& Boulet, L. (1994). Georges Cabanis, médecin de Brumaire. Paris: Fernand Lanore.

Saad, M. (2016). Cabanis, comprendre l'homme pour changer le monde. Paris: Garnier.

Staum, M. (1980). Cabanis: Enlightenment and Medical Philosophy in the French Revolution. Princeton: Princeton University Press.

Weisz, G. (1983). The Emergence of Modern Universities in France, 1863-1914. Princeton: Princeton University Press.

Williams, E. (1994). The Physical and the Moral: Anthropology, Physiology, and Philosophical Medicine in France, 1750-1850. Cambridge: Cambridge University Press.

Naomar Almeida-Filho

Professor no Instituto de Saúde Coletiva - Universidade Federal da Bahia Campus Canela

E-mail: naomaralmeida@gmail.com

Correspondência:

Naomar Almeida-Filho Instituto de Saúde Coletiva Universidade Federal da Bahia - Campus Canela Rua Basílio da Gama, s/n - Salvador-Bahia, Brasil CEP: 40110-040

Data de submissão: Setembro 2017

Data de avaliação: Janeiro 2018

Data de publicação: Dezembro 2018 